\title{
Three-dimensional drip infusion CT cholangiography in patients with suspected obstructive biliary disease: a retrospective analysis of feasibility and adverse reaction to contrast material.
} A Persson*1, N Dahlström², Ö Smedby ${ }^{1}$ and TB Brismar ${ }^{3}$

\author{
Address: ${ }^{1}$ Center for Medical Image Science and Visualization (CMIV), Linköping University Hospital, Sweden, ${ }^{2}$ Department of Radiology, \\ Hudiksvall Hospital, Sweden and ${ }^{3}$ Division of Radiology, Karolinska Institutet, Sweden \\ Email: A Persson* - anders.persson@cmiv.liu.se; N Dahlström - nils.dahlstrom@lg.se; Ö Smedby - orjan.smedby@imv.liu.se; \\ TB Brismar - torkel.brismar@karolinska.se \\ * Corresponding author
}

Published: 22 April 2006

BMC Medical Imaging 2006, 6:I doi:10.1 186/147/-2342-6-I
Received: 30 August 2005

Accepted: 22 April 2006

This article is available from: http://www.biomedcentral.com/I47/-2342/6/I

(C) 2006 Persson et al; licensee BioMed Central Ltd.

This is an Open Access article distributed under the terms of the Creative Commons Attribution License (http://creativecommons.org/licenses/by/2.0), which permits unrestricted use, distribution, and reproduction in any medium, provided the original work is properly cited.

\begin{abstract}
Background: Computed Tomography Cholangiography (CTC) is a fast and widely available alternative technique to visualise hepatobiliary disease in patients with an inconclusive ultrasound when MRI cannot be performed. The method has previously been relatively unknown and sparsely used, due to concerns about adverse reactions and about image quality in patients with impaired hepatic function and thus reduced contrast excretion. In this retrospective study, the feasibility and the frequency of adverse reactions of CTC when using a drip infusion scheme based on bilirubin levels were evaluated.
\end{abstract}

Methods: The medical records of patients who had undergone upper abdominal spiral CT with subsequent three-dimensional rendering of the biliary tract by means of CTC during seven years were retrospectively reviewed regarding serum bilirubin concentration, adverse reaction and presence of visible contrast media in the bile ducts at CT examination. In total, 153 consecutive examinations in 142 patients were reviewed.

Results: Contrast media was observed in the bile ducts at I 44 examinations. In I 10 examinations, the infusion time had been recorded in the medical records. Among these, 42 examinations had an elevated bilirubin value (>19 umol/L). There were nine patients without contrast excretion; 3 of which had a normal bilirubin value and 6 had an elevated value (25-I33 umol/L). Two of the 153 examinations were inconclusive. One subject $(0.7 \%)$ experienced a minor adverse reaction - a pricking sensation in the face. No other adverse effects were noted.

Conclusion: We conclude that drip infusion CTC with an infusion rate of the biliary contrast agent iotroxate governed by the serum bilirubin value is a feasible and safe alternative to MRC in patients with and without impaired biliary excretion.

In this retrospective study the feasibility and the frequency of adverse reactions when using a drip infusion scheme based on bilirubin levels has been evaluated. 


\section{Background}

For diagnosis of hepatobiliary disease, ultrasound and MR cholangiography (MRC) are most frequently used. Endoscopic Retrograde Cholangiography (ERC) is often regarded as the gold standard for visualising biliary disease. The latter modality is invasive, user-dependent and may induce pancreatitis. It should therefore not be performed in patients where intervention is less certain. Ultrasound, on the other hand, is easily tolerated by the patients and cost effective. The modality is, however, userdependent and the captured images are not easily understood by clinicians. MRC is superior in visualising the biliary system, and the images are appreciated by the surgeons at surgical planning. It does not require any contrast agent to visualise the bile ducts, and dilatation and gallstones in the common bile duct are easily detected [13]. Unfortunately, MRC cannot be performed in all patients and hospitals due to limited availability of MRI or due to contraindications. MRC is also often inconclusive in patients with air in the biliary system, e.g. after papillotomy or liver surgery with entero-hepatic anastomoses (such as Whipple's operation and Billroth 2). Surgical clips after cholecystectomy may also give artefacts mimicking a ductal cancer or a stone $[4,5]$. An alternative noninvasive method to ultrasound and MRC is therefore required.

Computed Tomography Cholangiography (CTC) is a fast and widely available technique to visualise hepatobiliary disease. Without contrast administration, multi detector CT has been reported to have a sensitivity of $65 \%-88 \%$ and a specificity of $84 \%-97 \%$ to detect gallstones $[6,7]$. Techniques to improve the sensitivity and specificity by administering biliary contrast media orally [8] or intravenously $[9,10]$ have been developed, but are not widespread. Possible explanations for infrequent use of CTC might be the low resolution of single detector helical CT and reports of an unacceptable high number of adverse events after injection of meglumine iotroxate [11]. With the development of multidetector $\mathrm{CT}$, the resolution of CTC exceeds that of MR. The number of adverse reactions with biliary contrast media has probably diminished by infusing the contrast media instead of injecting.

The aim of this retrospective study was to evaluate prolonged drip infusion CT cholangiography (CTC) in
Table I: The infusion rate of iotroxate (Biliscopin ${ }^{\circledR}$ ) was governed by the bilirubin level prior to the investigation. The same total amount of lodine (5 $\mathrm{g})$ was given to all patients.

\begin{tabular}{ll}
\hline Serum bilirubin & Infusion time \\
\hline$<20 \mu \mathrm{mol} / \mathrm{ml}$ & $40-60$ min \\
$21-40 \mu \mathrm{mol} / \mathrm{ml}$ & $1-3$ hours \\
$41-99 \mu \mathrm{mol} / \mathrm{ml}$ & $3-4$ hours \\
$>100 \mu \mathrm{mol} / \mathrm{ml}$ & 5 hours
\end{tabular}

patients with suspected obstructive biliary disease with respect to both feasibility and rate of adverse reactions after administration of the biliary contrast agent (iotroxate).

\section{Methods}

This is a retrospective study in 142 consecutive patients (68 men and 74 women, mean age 69 years, range $24-95$ years) referred for investigation of biliary disease during the period from January 1996 to January 2003. After approval by the ethics committee for the region, the medical records of all patients were retrospectively reviewed regarding bilirubin level, infusion time and adverse events. Adverse events were defined as any signs of reaction to contrast media that occurred after the injection, such as anaphylaxis, urticaria and respiratory distress.

\section{Administration of contrast media}

The serum bilirubin concentration was measured before CT examination using standard clinical laboratory methods used at the hospital. $100 \mathrm{ml}$ of meglumine iotroxate (Biliscopin $^{\circledast}$, Schering AG, Berlin, Germany) $50 \mathrm{mg} \mathrm{I} / \mathrm{ml}$ was administered by intravenous drip infusion. In order to allow longer infusion times, the solution volume was increased by dilution with isotonic sodium chloride (500 $\mathrm{ml}$ ). The infusion time was determined by the measured bilirubin level according to a schematic protocol (Table 1). Following the guidelines from the manufacturer, the drip infusion was started at a low infusion rate $(0.5 \mathrm{ml} / \mathrm{min})$ and increased to the desired infusion rate during the following 3-5 minutes. The CT scan was started immediately after the infusion was completed. For distension of the distal duodenum, the patients ingested two glasses of drinking water immediately before the CT examination. To evaluate

Table 2: CT acquisition parameters

\begin{tabular}{lllllll}
\hline Type of scanner & Collimation & Pitch & Increment & mAs & kV & $\begin{array}{l}\text { Number of } \\
\text { examinations }\end{array}$ \\
\hline Single Slice & $1 \times 5.0 \mathrm{~mm}$ & 1.5 & $1.5 \mathrm{~mm}$ & 200 & 120 & 103 \\
Multi-slice & $4 \times 2.5 \mathrm{~mm}$ & 6 & $1 \mathrm{~mm}$ & 130 & 120 & 46 \\
Multi-slice & $16 \times 0.75 \mathrm{~mm}$ & varying & $0.5 \mathrm{~mm}$ & 130 & 120 & 4 \\
\hline
\end{tabular}


Table 3: The bilirubin value, infusion time and final diagnosis in the nine cases where no secretion of contrast media was observed at DIC-CT.

\begin{tabular}{|c|c|c|c|}
\hline Bilirubin value, $\mu \mathrm{mol} / \mathrm{L}$ & $\underline{\text { Infusion time, minutes }}$ & Reported findings in medical records, final diagnosis & Reported findings at DIC-CT \\
\hline 133 & 120 & Hepatitis Type BI & wide bile duct \\
\hline 120 & 240 & Pancreatitis 1,2 & inconclusive \\
\hline 79 & 180 & Intraductal stone in choledochus and pancreatitis $7,2,6$ & Intraductal stone \\
\hline 73 & 120 & Cholecystitis 1,2 & wide bile duct \\
\hline 30 & unknown & Concrememt in choledochus $1,2,3,6$, & Intraductal stone \\
\hline 25 & unknown & $\begin{array}{l}\text { Concrement in choledochus, Total occlusion and Klatskin } \\
\text { tumour } 5,7\end{array}$ & Intraductal stone, tumour \\
\hline 16 & 60 & Distal stenosis in choledochus and pancreatitis $4,5,7$ & inconclusive \\
\hline 12 & 60 & Total occlusion in choledochus, pancreas tumour 2,3 & wide bile duct \\
\hline 8 & 60 & $\begin{array}{l}\text { Post operative cholangitis/cholecystitis with bile fistula and } \\
\text { leakagel } 1,6,7\end{array}$ & fluid-filled cavity \\
\hline
\end{tabular}

The method by which the final diagnosis was made is indicated by the superscript numbers where $\mathrm{I}=$ laboratory findings, $2=$ ultrasound, $3=$ ultrasound with fine needle biopsy, $4=\mathrm{MRCP}, 5=$ operation, $6=\mathrm{ERCP}$ and $7=\mathrm{PTC}$.

compliance to the protocol, the medical records were reviewed regarding the given infusion time at the ward.

\section{Scanning parameters}

Patients were scanned in the right oblique position by means of thin-section single-breath-hold helical CT in the cranio-caudal direction. Specific scan protocols varied depending on the CT scanner available at the time of examination (Table 2). Between December 1995 and November 1999, 102 patients were scanned with a singleslice CT scanner (Somatom A; Siemens Medical Systems, Forcheim, Germany). From December 1999 to November 2002, a 4-slice multi-detector CT scanner (Somatom Volume Zoom; Siemens Medical Systems, Forcheim, Germany) was used in 44 exams. Between December 2002 and January 2003, a 16-slice multi-detector CT scanner (Somatom Sensation16; Siemens Medical Systems, Forcheim, Germany) was used in 6 exams.

\section{Evaluation of contrast media excretion}

The attenuation in choledochus and liver was obtained retrospectively by measurement in the restored digital images in all examinations with bilirubin $>19 \mu \mathrm{mol} / \mathrm{L}$ ( $\mathrm{n}$ $=42$ ), as well as in 67 individuals also described in another study [12], 19 of the latter with bilirubin $>19$ $\mu \mathrm{mol} / \mathrm{L}$. In total, attenuation values from $90(=42+67-$ 19) patients were obtained.

\section{Review of literature}

A MEDLINE search was performed for all clinical studies in English published during the period 1975-2004 concerning iotroxate, using the words "Biliscopin" or "iotroxate". All articles were reviewed for reports regarding adverse events. The pooled frequency of adverse events was calculated for all articles with a number of patients $>100$ where the contrast had been infused for 30 minutes or more.

\section{Statistical methods}

Data are given as mean ( \pm standard deviation). Frequencies are given with their $95 \%$ confidence interval, computed with normal approximation.

\section{Results}

Out of 153 examinations performed in 142 patients, one subject experienced a minor reaction (pricking sensation in the face) following the administration of $70 \mathrm{ml}$ of contrast. In this patient, the pre-exam bilirubin value was nor$\mathrm{mal}(11 \mu \mathrm{mol} / \mathrm{L})$ and the planned infusion time was 60 minutes. Four weeks later, the same patient successfully underwent a repeated CT cholangiography using the same infusion rate without any adverse reactions. In the other 141 patients (151 examinations), no adverse reaction was noted in the medical records. Thus, the observed frequency of adverse reactions in this material was $1 / 153$ $(0.65 \%)$. Of the 153 examinations, 10 were performed in out-patients. These patients normally stay in the radiology department one hour after the contrast injection has been completed. Due to the retrospective nature of this study, late mild adverse advents may not have been recorded in these 10 patients. More severe adverse reactions such as a skin rash, itches, etc. are, however, usually reported to the hospital by the patients and according to the routines of the hospital, adverse reactions are always noted in the medical records after an X-ray examination. The hospital is the only one in the district and no notes could be found about adverse advents in the patients' files (files from departments of radiology, surgery and internal medicine were reviewed).

The mean bilirubin value was $20( \pm 25) \mu \mathrm{mol} / \mathrm{L} .42$ patients had an elevated bilirubin value (defined as $>19$ $\mu \mathrm{mol} / \mathrm{L}$ ). Information regarding the infusion time used at the ward had been noted in the medical records in 110 out of 153 examinations. The mean infusion time was $82( \pm$ 


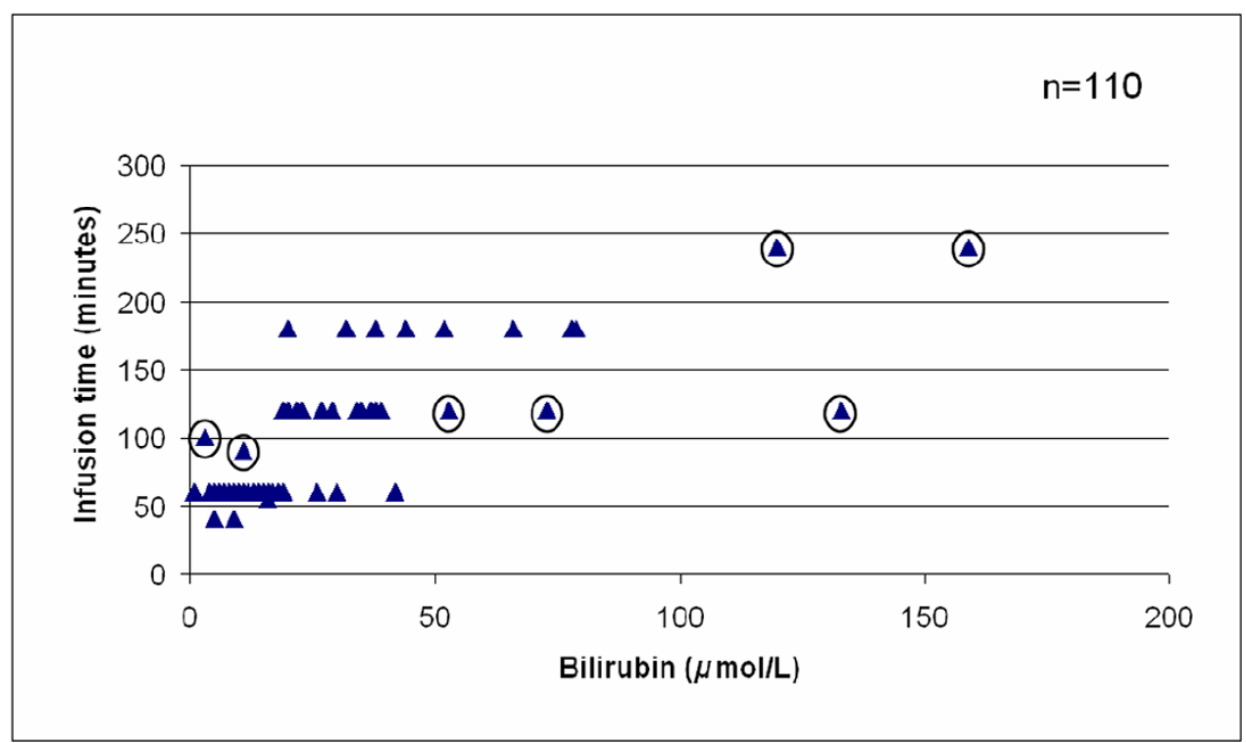

\section{Figure I}

The infusion time of iotroxate (Biliscopin ${ }^{\circledR}$ ) in relation to bilirubin level prior to the investigation. The recommended infusion times were followed in 103 out of the 110 cases $(94 \%)$ where information on infusion time was found in the medical records. Cases in which the recommendations were not followed are encircled $(n=7)$. Unfortunately, none of the three $(3 / 1 / 0)$ examinations with a bilirubin value $>100 \mu \mathrm{mol} / \mathrm{ml}$ was performed according to the infusion scheme. The patient with the highest bilirubin value $(159 \mu \mathrm{mol} / \mathrm{ml})$ had good diagnostic excretion of contrast in the bile ducts, whereas the other two had no excretion.

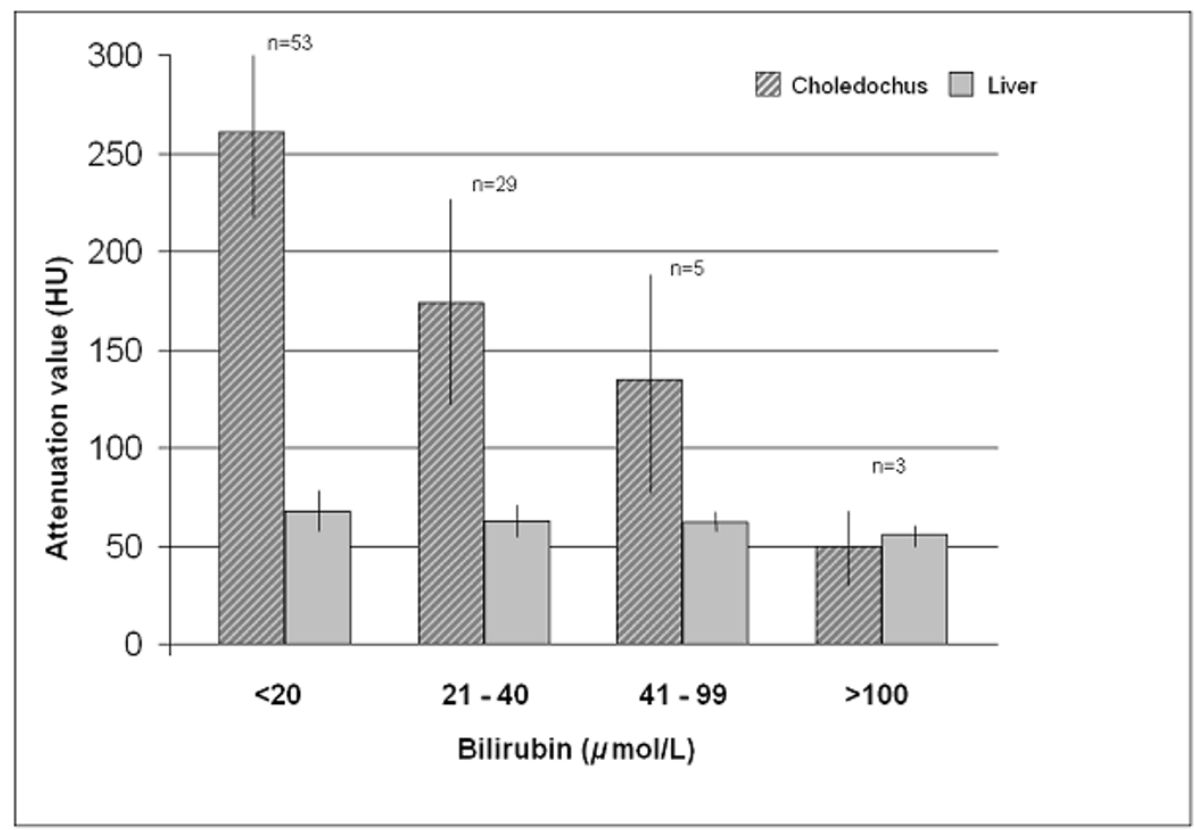

Figure 2

Attenuation in choledochus and liver at DIC-CT as a function of serum bilirubin before the examination.

42) minutes. Disregarding potential measurement errors of 
Table 4: Published studies on the frequency of adverse reactions at infusion of iotroxate at intravenous cholangiography. Included are all studies with at least 100 patients using an infusion time of at least $30 \mathrm{~min}$. The severity of the reactions is graded as reported. The number in superscript denotes the corresponding reference.

\begin{tabular}{|c|c|c|c|c|c|c|}
\hline & No. of Patients & Total & Minor & Intermediate & Severe & Fatal \\
\hline Nilsson 1987।I & I 446 & 49 (3.4\%) & $4 \mathrm{l}(2.9 \%)$ & $5(0.35 \%)$ & $3(0.21 \%)$ & 0 \\
\hline Daly 198731 & 286 & $4(1.4 \%)$ & $4(1.4 \%)$ & 0 & 0 & 0 \\
\hline Joyce $\left.199\right|^{32}$ & 100 & $2(2.0 \%)$ & $2(2.0 \%)$ & 0 & 0 & 0 \\
\hline Wigmore $1993^{33}$ & 100 & 0 & 0 & 0 & 0 & 0 \\
\hline Patel $1993^{34}$ & 113 & $3(2.7 \%)$ & $3(2.7 \%)$ & 0 & 0 & 0 \\
\hline Grunshaw $1993^{35}$ & 137 & $4(2.9 \%)$ & $3(2.2 \%)$ & I (0.7\%) & 0 & 0 \\
\hline ASacharias $1995^{36}$ & $106 \mid$ & II (I.0\%) & & II A $(1.0 \%)$ & 0 & 0 \\
\hline Kwon $1998^{16}$ & 440 & $2(0.5 \%)$ & $2(0.5 \%)$ & 0 & 0 & 0 \\
\hline Kitami $2006^{37}$ & 220 & $3(1.4 \%)$ & $3(1.5 \%)$ & 0 & 0 & 0 \\
\hline Okada $2005^{17}$ & 432 & $4(0.9 \%$ & $4(0.9 \%)$ & 0 & 0 & 0 \\
\hline Hirao $2000^{22}$ & 120 & $2(1.7 \%)$ & $2(1.7 \%)$ & 0 & 0 & 0 \\
\hline BTakamatsu 200438 & 132 & I $(0.8 \%)$ & I $(0.8 \%)$ & 0 & 0 & 0 \\
\hline Total & 4587 & 85 & 65 & 17 & 3 & 0 \\
\hline $\begin{array}{l}\text { Frequency ( } 95 \% \\
\text { confidence limits) }\end{array}$ & & $1.9 \%(1.5 \%-2.2 \%)$ & $1.4 \%(1.1 \%-1.8 \%$ & $0.4 \%(0.2 \%-0.5 \%)$ & $0.1 \%(0-0.1 \%)$ & 0 \\
\hline
\end{tabular}

ANo difference was made between minor and intermediate adverse events.

B The infusion time was 25-30 min. The number of complications in the article was reported by personal communication.

at most $2 \mu \mathrm{mol} / \mathrm{L}$, seven infusions (5\%) had not been performed according to the protocol. Five of these received the infusion too fast and 2 too slow (Fig. 1). All three patients with a bilirubin $>100 \mu \mathrm{mol} / \mathrm{L}$ were among the seven patients who did not receive the correct infusion rate. The intended infusion rate ( 5 hours) could therefore not be evaluated.

Excretion of contrast media was observed in 93\% (143/ 153 ) of all exams (one examination aborted due to potential contrast reaction). In patients with elevated serum bilirubin ( $>19 \mu \mathrm{mol} / \mathrm{L}$ ) contrast media in the bile was observed in 36 out of 42 patients (86\%). No visible secretion of contrast was reported in 9 patients (Table 3 ). In three of these, the infusion protocol had not been followed, with too fast infusion (bilirubin $73-133 \mu \mathrm{mol} / \mathrm{L}$ ). The final diagnoses in the patients with no visible secretion are also shown in Table 3. Three of these had occlusive intraductal stones, all of which were reported at the CTC. Two patients had a malignancy affecting the bile ducts. One of these was reported at CTC and the other showed signs of dilated bile ducts.

The remaining 4 patients had hepatitis, pancreatitis, cholangitis or cholecystitis.

The observed attenuation in choledochus and liver for different serum bilirubin levels is shown in Fig. 2.

\section{Review of literature}

In total, 42 original publications in English were found. Those with more than 100 patients and with an infusion time of 30 minutes or more are listed in Table 4 as well as the pooled number of adverse events (2.27\%).

\section{Discussion}

When the bile ducts are obstructed, excretion of bile and contrast media is decreased. It has therefore been assumed that CT cholangiography cannot be performed in patients with elevated serum bilirubin concentration $[9,10]$. In this study, the infusion rate of the contrast media was adjusted to the bilirubin value (Table 1 ). The aim was to keep the concentration within the excretory capacity of the hepatocytes in order to optimise the concentration in bile. By using this scheme, contrast excretion into the bile ducts was observed in $93 \%$ of all exams. In patients with elevated serum bilirubin $(>19 \mu \mathrm{mol} / \mathrm{L})$, contrast media in the bile was observed in $86 \%$. Excretion of contrast media was noted even when the bilirubin concentration was as high as 159 $\mu \mathrm{mol} / \mathrm{L}$ (Fig. 3, 4). It has previously been recommended not to perform CTC in patients with bilirubin $>50 \mu \mathrm{mol} / \mathrm{L}(3$ $\mathrm{mg} / \mathrm{dL}$ ) [14]. In this study, excretion was observed in four out of eight patients with bilirubin $>50 \mu \mathrm{mol} / \mathrm{L}$. In three of those without contrast excretion, however, the infusion protocol had not been followed (too fast infusion). Although absence of contrast media in the bile ducts is more likely in patients with greatly elevated bilirubin, CTC is not useless in these patients - only two of the nine examinations without contrast excretion were inconclusive. In the other seven cases, CTC findings could guide the referring physician to other examinations and the final diagnosis (Table 3 ).

The lack of excretion may also constitute valuable information. Patients without excretion are likely to have either a total occlusion of the main bile duct/choledochus 


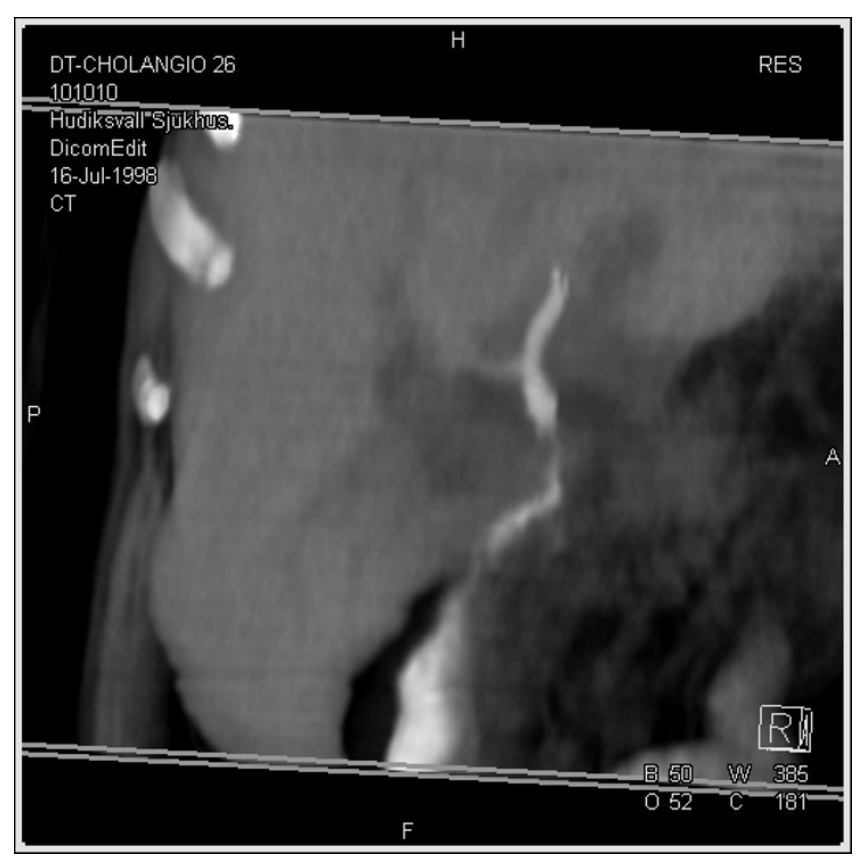

Figure 3

In spite of an elevated bilirubin value, a good contrast excretion can be observed when a prolonged infusion time is used. In this case, the bilirubin value was $78 \mu \mathrm{mol} / \mathrm{L}$ and the infusion time was 3 hours. Final diagnosis was status post choledochoduodenostomy.

or severely impaired hepatocyte function. The bilirubin concentration, if not already considerably elevated, is likely to increase in these patients. In this study, the lack of excretion could be explained by the final diagnosis in all patients (Table 3 ).

The protein-binding characteristics essential for biliary contrast media increase the risk of adverse reactions $[11,15]$. In a previously published review of the literature on the frequency of adverse reactions in examinations with short injection time ( $<10 \mathrm{~min})$, the pooled number of adverse events was three times higher (16\% vs. 5\%) than after infusion ( $>30 \mathrm{~min}$ ) of the same amount of contrast media [11]. The frequency of adverse events of iotroxate (Biliscopin ${ }^{\circledR}$ ) at infusion has been reported to be as high as $3.4 \%$, with a pooled frequency of $1.9 \%$ (Table 4). It has been proposed that the tolerance of intravenous biliary contrast media is improved when a slow infusion technique is used (up to one hour of infusion) [16,17]. Our study supports this proposal, as there was only one adverse reaction, which was mild, in 142 patients and 153 examinations $(0.65 \%)$.

After an inconclusive ultrasound examination, MRC has the advantage of not exposing the patient to radiation and contrast media. On the other hand, in many clinical situations

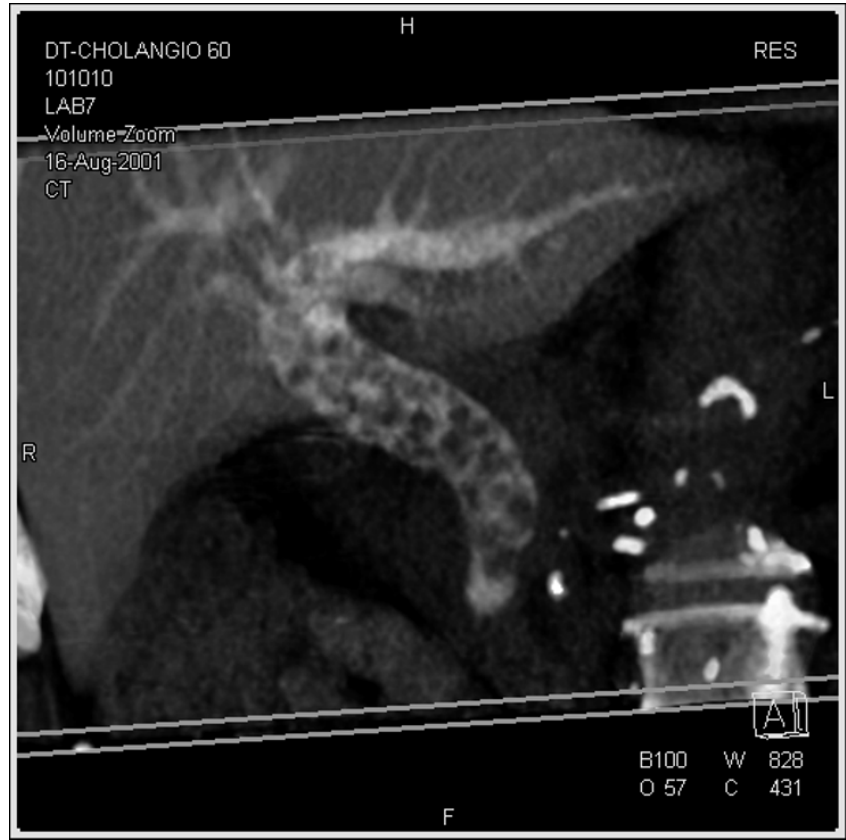

\section{Figure 4}

$A$ vast number of biliary stones visualized in the choledochus duct. Pre-examination bilirubin was $29 \mu \mathrm{mol} / \mathrm{L}$ (infusion time not noted in the medical record). ERCP verified the bile duct stones.

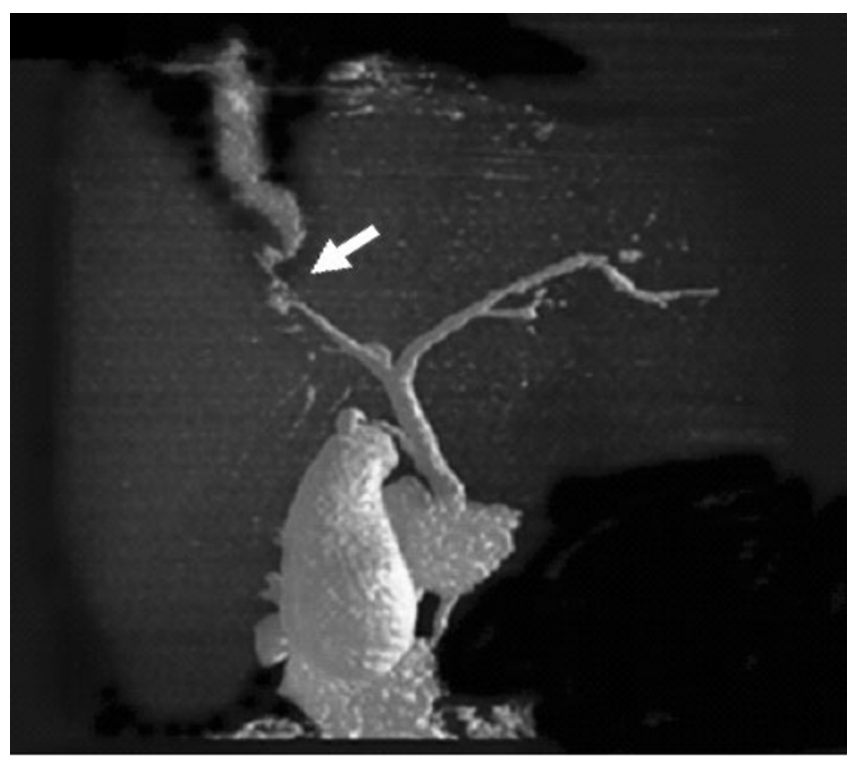

\section{Figure 5}

Traffic accident with a liver rupture and leakage from a small bile duct. The DIC-CT examination led the surgeon correctly to the leaking bile duct (arrow). The diameter of the ruptured bile duct was $1 \mathrm{~mm}$. 
the availability of MRI examinations with short notice is limited. The sensitivity and specificity of contrast enhanced CTC to detect choledocholithiasis are comparable to those of MRC (sensitivity $86-93 \%$ and $80-95 \%$, respectively, and specificity $94-100 \%$ and $88-96 \%$, respectively) $[3,8,18,19]$. CTC is also faster than MRC, which may be of importance in patients with difficulties in lying in the supine position for a prolonged time or when evaluating severely ill patients.

CTC has been used to preoperatively evaluate aberrant bile ducts before laparoscopic cholecystectomy. The frequency of anatomic variants that may affect the outcome of laparoscopic cholecystectomy was estimated to be 15\% with CTC $[16,20,21]$. In clinical practise, the frequency of bile duct injuries is about $0.5-1.5 \%[22,23]$. The potential value of pre-operative mapping of the biliary system by using CTC must therefore be weighed against the cost and radiation.

With injection of contrast media via biliary drainage catheters, CTC has been successfully used to visualize the extent of ductal invasion by hilar carcinoma [24]. Whether administration of contrast media orally or intravenously may achieve similar results in patients without drainage has not been shown.

In clinical practise, CTC has been reported to be the preferred modality to evaluate living donors prior to liver transplantation [25]. The main reported advantage to MRI and MRC was the superior mapping of the biliary tree [26] - in other respects the two modalities were considered equivalent for the planning [25]. After introduction of CTC, the use of an intraoperative cholangiogram has been reported to be significantly reduced at living donor liver transplantation [27]. After liver surgery, there is a risk of biliary leaks. In these patients, and in patients with traumatic rupture of the biliary tree, CTC may be useful to demonstrate the leak (fig 5) [28]. Cholescintigraphy can also demonstrate biliary leaks [29], but the resolution is low compared to CT. To our knowledge, there is no other non-invasive technique to visualise a leakage from the biliary tree (unless a functioning external biliary drainage is present, enabling a secondary cholangiography).

CTC has been shown to provide kinetic and functional information [30]. This is also possible in contrast enhanced MRC when hepatocyte specific contrast media is used (Gd-BOPTA and Gd-EOB-BOPTA). Further studies are required to evaluate whether contrast enhanced MRC or CTC should be preferred to evaluate biliary kinetics.

The main disadvantages of CTC compared to MRC are the use of radiation and contrast media. In our study, including the literature review, the frequency and severity of adverse reactions was low when infusing the contrast media. The disadvantage of infusion is the need of supervision, which is impractical in a radiology department. In our setting, this problem was solved by admitting the patients to a ward for infusion prior to CTC.

\section{Conclusion}

This study indicates that drip infusion CTC with an infusion rate of iotroxate governed by the serum bilirubin concentration is a feasible and safe tool in patients with and without impaired biliary excretion. In addition to those with inconclusive MRC or contraindications, CTC is a diagnostic alternative in patients already admitted to the hospital for whom a reliable diagnosis or mapping of the biliary tree is required within a limited time. In younger patients, non-ionising methods (i.e. MRC or a repeated ultrasound examination) should be preferred.

\section{Competing interests}

The author(s) are not aware of any conflicts of interest relating to this article. For the linguistic revision of this manuscript AP received from Schering AG a support equalling to 300 Euro.

\section{Authors' contributions}

AP was responsible for study design, data collection, was one of the viewers, performed literature search and manuscript preparation. ND was one of the viewers. ÖS was responsible for study design and statistical analyses. ТВ was responsible for study design, was one of the viewers, performed literature search and finalized manuscript. All authors contributed during manuscript preparation, and read and approved the final manuscript.

\section{References}

I. Aube C, Delorme B, Yzet T, Burtin P, Lebigot J, Pessaux P, GondryJouet $C$, Boyer J, Caron $C$ : MR cholangiopancreatography versus endoscopic sonography in suspected common bile duct lithiasis: a prospective, comparative study. Am J Roentgenol 2005, 184:55-62.

2. Boraschi P, Gigoni R, Braccini G, Lamacchia M, Rossi M, Falaschi F: Detection of common bile duct stones before laparoscopic cholecystectomy. Evaluation with MR cholangiography Acta Radiol 2002, 43:593-598.

3. Kim YJ, Kim MJ, Kim KW, Chung JB, Lee WJ, Kim JH, Oh YT, Lim JS, Choi JY: Preoperative evaluation of common bile duct stones in patients with gallstone disease. Am J Roentgenol 2005, 184:1854-1859.

4. Irie H, Honda H, Kuroiwa T, Yoshimitsu K, Aibe H, Shinozaki K, Masuda K: Pitfalls in MR cholangiopancreatographic interpretation. Radiographics 200I, 21:23-37.

5. Watanabe Y, Dohke M, Ishimori T, Amoh Y, Okumura A, Oda K, Koike S, Dodo Y: Diagnostic pitfalls of MR cholangiopancreatography in the evaluation of the biliary tract and gallbladder. Radiographics 1999, 19:415-429.

6. Soto JA, Alvarez O, Munera F, Velez SM, Valencia J, Ramirez N: Diagnosing bile duct stones: comparison of unenhanced helical CT, oral contrast-enhanced CT cholangiography, and MR cholangiography. Am J Roentgenol 2000, 175: I I27-I I34.

7. Neitlich JD, Topazian M, Smith RC, Gupta A, Burrell MI, Rosenfield AT: Detection of choledocholithiasis: comparison of unenhanced helical CT and endoscopic retrograde cholangiopancreatography. Radiology 1997, 203:753-757. 
8. Soto JA, Velez SM, Guzman J: Choledocholithiasis: diagnosis with oral-contrast-enhanced CT cholangiography. Am J Roentgenol 1999, 172:943-948.

9. Stockberger SM, Wass JL, Sherman S, Lehman GA, Kopecky KK: Intravenous cholangiography with helical CT: comparison with endoscopic retrograde cholangiography. Radiology 1994, 192:675-680.

10. Van Beers BE, Lacrosse M, Trigaux JP, de Cannieri L, De Ronde T, Pringot J: Noninvasive imaging of the biliary tract before or after laparoscopic cholecystectomy: use of three dimensional spiral CT cholangiography. Am J Roentgenol 1994, 162:1331-1335.

II. Nilsson U: Adverse reactions to iotroxate at intravenous cholangiography. A prospective clinical investigation and review of the literature. Acta Radiologica 1987, 28:57|-575.

12. Persson A, Dahlstrom N, Smedby O, Brismar TB: Volume rendering of three-dimensional drip infusion $C T$ cholangiography in patients with suspected obstructive biliary disease: a retrospective study. BrJ Radiol 2005, 78(936): 1078-85.

13. Breen DJ, Nicholson AA: The clinical utility of spiral CT cholangiography. Clin Radiol 2000, 55:733-739.

14. Takahashi M, Saida Y, Itai Y, Gunji N, Orii K, Watanabe Y: Reevaluation of spiral CT cholangiography: basic considerations and reliability for detecting choledocholithiasis in $\mathbf{8 0}$ patients. J Comput Assist Tomogr 2000, 24:859-865.

15. Pasanen P, Partanen K, Pikkarainen P, Alhava E, Pirinen A, Janatuinen $E$ : Ultrasonography, CT, and ERCP in the diagnosis of choledochal stones. Acta Radiol 1992, 33:53-56.

16. Kwon $\mathrm{AH}$, Inui H, Imamura A, Uetsuji S, Kamiyama Y: Preoperative assessment for laparoscopic cholecystectomy: feasibility of using spiral computed tomography. Ann Surg 1998, 227:35I-356.

17. Okada M, Fukada J, Toya K, Ito R, Ohashi T, Yorozu A: The value of drip infusion cholangiography using multidetector-row helical CT in patients with choledocholithiasis. Eur Radiol 2005, I 5:2। $140-5$.

18. Gibson RN, Vincent JM, Speer T, Collier NA, Noack K: Accuracy of computed tomographic intravenous cholangiography (CTIVC) with iotroxate in the detection of choledocholithiasis. Eur Radiol 2005, I 5: 1634-42.

19. Boraschi P, Gigoni R, Braccini G, Lamacchia M, Rossi M, Falaschi F: Detection of common bile duct stones before laparoscopic cholecystectomy. Evaluation with MR cholangiography. Acta Radiol 2002, 43:593-598.

20. Izuishi K, Toyama $Y$, Nakano S, Goda F, Usuki H, Masaki T, Maeta H: Preoperative assessment of the aberrant bile duct using multislice computed tomography cholangiography. Am J Surg 2005, 189:53-55.

21. Hirao K, Miyazaki A, Fujimoto T, Isomoto I, Hayashi K: Evaluation of aberrant bile ducts before laparoscopic cholecystectomy: helical CT cholangiography versus MR cholangiography. Am J Roentgenol 2000, I75:7| 3-20.

22. Soderlund C, Frozanpor F, Linder S: Bile duct injuries at laparoscopic cholecystectomy: a single-institution prospective study. Acute cholecystitis indicates an increased risk. World J Surg 2005, 29:987-993.

23. MacFadyen BV Jr, Vecchio R, Ricardo AE, Mathis CR: Bile duct injury after laparoscopic cholecystectomy. The United States experience. Surg Endosc 1998, | 2:3 |5-32|

24. Kim HJ, Kim AY, Hong SS, Kim MH, Byun JH, Won HJ, Shin YM, Kim PN, Ha HK, Lee MG: Biliary ductal evaluation of hilar cholangiocarcinoma: three-dimensional direct multi-detector row CT cholangiographic findings versus surgical and pathologic results - feasibility study. Radiology 2006, 238:300-8.

25. Schroeder T, Malago M, Debatin JF, Goyen M, Nadalin S, Ruehm SG: "All-in-one" imaging protocols for the evaluation of potential living liver donors: comparison of magnetic resonance imaging and multidetector computed tomography. Liver Transpl 2005, I I (7):776-87.

26. Yeh BM, Breiman RS, Taouli B, Qayyum A, Roberts JP, Coakley FV Biliary tract depiction in living potential liver donors: comparison of conventional MR, mangafodipir trisodiumenhanced excretory MR, and multi-detector row CT cholangiography - initial experience. Radiology 2004, 230:645-5I.

27. Wang ZJ, Yeh BM, Roberts JP, Breiman RS, Qayyum A, Coakley FV: Living donor candidates for right hepatic lobe transplanta- tion: evaluation at CT cholangiography - initial experience. Radiology 2005, 235:899-904.

28. Dinkel HP, Moll R, Gassel HJ, Knupffer J, Timmermann W, Fieger M, Schindler G: Helical CT cholangiography for the detection and localization of bile duct leakage. Am J Roentgenol 1999, 173(3):613-7.

29. Sandoval BA, Goettler CE, Robinson AV, O'Donnell JK, Adler LP, Stellato TA: Cholescintigraphy in the diagnosis of bile leak after laparoscopic cholecystectomy. Am Surg 1997, 63:6 II-6.

30. Eracleous E, Genagritis M, Papanikolaou N, Kontou AM, Prassopoullos P, Chrysikopoulos H, Allan P, Gourtsoyiannis N: Complementary role of helical CT cholangiography to MR cholangiography in the evaluation of biliary function and kinetics. Eur Radiol 2005, 1 5:2 130-2139.

31. Daly J, Fitzgerald T, Simpson Cl: Pre-operative intravenous cholangiography as an alternative to routine operative cholangiography in elective cholecystectomy. Clin Radiol 1987, 38:161-163.

32. Joyce WP, Keane R, Burke GJ, Daly M, Drumm J, Egan TJ, Delaney PV: Identification of bile duct stones in patients undergoing laparoscopic cholecystectomy. Br J Surg 1991, 78: I I74-I I 76.

33. Wigmore SJ, Wood K, Rainey JB, Macleod DA: Intravenous cholangiography in preoperative assessment of patients considered for laparoscopic cholecystectomy. Surg Laparosc Endosc I991, 4:254-257.

34. Patel JC, Mclnnes GC, Bagley JS, Needham G, Krukowski ZH: The role of intravenous cholangiography in pre-operative assessment for laparoscopic cholecystectomy. Br J Radiol 1993, 66: II25-1 I 27.

35. Grunshaw ND, Lansdown MRJ, Milkins RC: The intravenous cholangiogram - time for reappraisal in the age of laparoscopic cholecystectomy. Minimally invasive Therapy 1993, 2(Suppl):35.

36. Sacharias N: Safety of Biliscopin. Australas Radiol 1995, 39:10I.

37. Kitami M, Takase K, Murakami G, Ko S, Tsuboi M, Saito H, Higano S, Nakajima $Y$, Takahashi S: Types and frequencies of biliary tract variations associated with a major portal venous anomaly: analysis with multi-detector row CT cholangiography. Radiology 2006, 238(1):156-66.

38. Takamatsu S, Goseki N, Nakajima K, Teramoto K, Iwai T, Arii S: Distributing pattern of the bile duct of the caudate lobe on computed tomography with drip infusion cholangiography and its surgical significance. Hepatogastroenterology 2004, 5 I:29-32.

\section{Pre-publication history}

The pre-publication history for this paper can be accessed here:

http://www.biomedcentral.com/1471-2342/6/1/prepub

Publish with Bio Med Central and every scientist can read your work free of charge

"BioMed Central will be the most significant development for disseminating the results of biomedical research in our lifetime. "

Sir Paul Nurse, Cancer Research UK

Your research papers will be:

- available free of charge to the entire biomedical community

- peer reviewed and published immediately upon acceptance

- cited in PubMed and archived on PubMed Central

- yours - you keep the copyright

Submit your manuscript here:

http://www.biomedcentral.com/info/publishing_adv.asp
BioMedcentral 